\title{
Egocentrism, allocentrism, and Asperger syndrome
}

\author{
Uta Frith *, Frederique de Vignemont \\ Institute of Cognitive Neuroscience, University College London, UK
}

Received 29 October 2004

Available online 29 June 2005

\begin{abstract}
In this paper, we attempt to make a distinction between egocentrism and allocentrism in social cognition, based on the distinction that is made in visuo-spatial perception. We propose that it makes a difference to mentalizing whether the other person can be understood using an egocentric ("you") or an allocentric ("he/ she/they") stance. Within an egocentric stance, the other person is represented in relation to the self. By contrast, within an allocentric stance, the existence or mental state of the other person needs to be represented as independent from the self. We suggest here that people with Asperger syndrome suffer from a disconnection between a strong naïve egocentric stance and a highly abstract allocentric stance. We argue that the currently used distinction between first-person and third-person perspective-taking is orthogonal to the distinction between an egocentric and an allocentric stance and therefore cannot serve as a critical test of allocentrism.

(c) 2005 Published by Elsevier Inc.
\end{abstract}

Keywords: Perspective-taking; Theory of mind; Self-awareness; Mentalizing; Social cognition; Autism; Metarepresentation; Executive functions; Central coherence

\section{Introduction}

Bernard was a precocious child. He invented complicated games that the other children did not understand and he had fits of rage when they refused to play. At school, Bernard was never the

\footnotetext{
* Corresponding author

E-mail address: u.frith@ucl.ac.uk (U. Frith).
} 
one selected for a team and he found this humiliating. His teachers appreciated his high intelligence but found that he was quite unable to work with others in a group. He learned in his own way, refusing to fit in with the syllabus.

When he was an adolescent he became obsessed with a particular classmate who was highly popular. He was surprised that this boy made an official complaint when he had copied every detail of his attire. He said he just wanted to be equally popular. Bernard increasingly showed signs of acute anxiety and was finally referred to a specialist, who diagnosed him as having Asperger syndrome. The diagnosis was very important to him because, according to Bernard, he now understood why he was so different and why he had so many problems with what he referred to as the social rules.

He avidly reads books and watches documentaries that are relevant to his areas of interest, but he never reads novels or watches TV drama, which he claims are not worth the bother and a waste of time. He lives with his parents but complains about having to fit in with their rules. When his mother had to go to hospital, he was angry that his daily routine was ruined. On the other hand, when one day she had a gastric upset and could only sip weak tea, Bernard brought her a big bag of fish and chips - to cheer her up. His mother accepts his blatant egocentrism as a part of his condition and she takes it with a sense of humour. She laughingly related that Bernard's greatest wish is to live alone in a big house served by a large number of robots.

This vignette gives an impression of the limited, but by no means absent social competence of a not untypical individual with Asperger syndrome. In current clinical practice Asperger syndrome is still a controversial diagnosis, but it tends to be most often used for the milder forms of autistic disorder combined with high verbal ability (Frith, 2004; Macintosh \& Dissanayake, 2004). In the following we will use the abbreviation AS to refer to Asperger syndrome. Since research has not succeeded in delineating clear-cut differences between the cognitive characteristics of high-functioning adults with autism and those with Asperger syndrome, our AS category includes both.

For our present purposes we consider AS individuals with normal or superior intellectual ability who show the following features: difficulty in reciprocal social interaction, communication impairments, a lack of flexibility with obsessive tendencies, and a single-minded pursuit of narrow interests. Here we focus exclusively on the social impairment. We believe that a deeper analysis of this impairment is needed than has hitherto been provided by the notion of a lack of "theory of mind," also known as mindblindness or mentalizing failure (e.g., Baron-Cohen, 1995; Frith, 2001; Happé et al., 1996).

AS individuals are often able to pass standard theory of mind tests, yet their capacity to mentalize seems fragile. Could it be that their successful mentalizing is limited by a high degree of egocentrism? Indeed, Asperger (1944) described the children he identified as "egocentric in the extreme." Later on in this paper we will give specific examples to illustrate the type of egocentrism seen in AS. First, however, we will attempt to make a distinction between egocentrism and allocentrism.

\section{Different roles and different stances}

Dennett (1987) introduced the notion of the intentional stance, which can be defined as a strategy for understanding an entity's behaviour by treating it as if it were a rational agent. We will not 
address here the question of rationality, but instead we will propose a distinction between two possible kinds of stance that one can adopt towards an agent: the egocentric and the allocentric stance. When we adopt an egocentric stance we understand the other person relative to ourselves, which allows us to locate him in our social world and to interact with him. For example, Piaget pointed out that young children can easily understand the relationship between themselves and their mother but it is more difficult for them to understand that their mother is also their father's wife. This understanding requires an allocentric stance, which represents the other independently of one's own current relation with her. The allocentric stance allows us to generate a folk psychology, which generally applies to all people.

We will show first that this distinction between egocentrism and allocentrism is orthogonal to the distinction between first-person and third-person perspective. As this distinction has rarely been addressed in the literature on mindreading, we will offer some speculations, which we will test on specific examples of problems in social behaviour as experienced by AS individuals.

\subsection{First-person versus third-person role-taking}

Most of the literature on the topic of theory of mind has focused on the processes involved in the interpretation of another person's behaviour. For instance, standard false belief tasks focus solely on belief ascription to others, taking for granted that the children know their own beliefs. The main disagreement between theory-theory and simulation-theory concerns the mechanisms underlying the ascription of mental states to others (Nichols \& Stich, 2003). Indeed, these theories very rarely address the question of self-ascription. However, theory of mind is not restricted to the understanding of others, but also includes self-knowledge. A full account of mindreading should thus include a theory of both third-person and first-person ascription.

Some studies have investigated the relationship between first-person and third-person mindreading. For instance, both Gopnik (1993) and Happé (2003) argue that children acquire knowledge of their own mental states and knowledge of the mental states of others at the same time and show the same difficulties in both cases. According to Gopnik and Astington (1988), 3-year-old children have the same difficulty in understanding that a belief could be false, whether it is their own or someone else's. More generally, there seems to be a striking parallel in performance on first- and third-person tasks. However, these data are controversial, as most of the experiments concern knowledge of one's own past mental states, rather than current ones (for a review, see Nichols \& Stich, 2003).

Using brain imaging, Vogeley and collaborators have systematically investigated the neural basis of first-person and third-person spatial and mental perspectives. Subjects were asked to describe a visual scene from a first-person visuo-spatial point of view or from the point of view of an avatar (Vogeley et al., 2004). The results show some brain activation common to both points of view in occipital, parietal, and prefrontal areas, but also differences between first-person perspective (medial prefrontal cortex, posterior cingulate cortex, and superior temporal cortex bilaterally) and third-person perspective (medial superior parietal and right premotor cortex). Similarly, Vogeley et al. (2001) show that in addition to joint neural mechanisms, different brain areas are activated whether subjects ascribe mental states to others (anterior cingulate cortex) or to themselves (right temporo-parietal junction). Ruby and Decety (2003) also emphasize the 
involvement of the inferior parietal cortex in self- versus other-awareness. These results are consistent with the literature about the sense of agency (Farrer \& Frith, 2002; Ruby \& Decety, 2001).

The question raised across these studies is whether the processes involved in mentalizing vary according to the target (self versus other) to whom you attribute mental states. They require subjects to take the target's perspective on the world and as such, are often labelled "perspective-taking" tasks. However, we want to argue that this label is confusing, particularly if we refer to spatial perspective-taking. We can trace this conceptual confusion in developmental psychology to Piaget himself.

Piaget's original ideas on mental development have focused on egocentrism in early childhood, based on experimental studies such as the famous three mountains problem (Piaget \& Inhelder, 1948/1956). Here a child has to indicate which view an observer would have from a different position than the child's own (see Fig. 1).

Using this paradigm, children up to about age 7 , at the so-called pre-operational stage, were found to lack the ability to appreciate a different viewpoint from their own. Only when they entered the concrete-operational stage, between 7 and 12, did they achieve "decentring." This allows them to take account of multiple aspects of a task to solve it. According to Piaget, then, egocentrism, understood as an inability to decentre and take another person's perspective, is the norm in young children. A variant of the three mountains paradigm has been used by Hobson (1984) as a way of assessing social role-taking in autistic children. He found that autistic children were not more impaired in this task than other children of the same intellectual level who were not socially

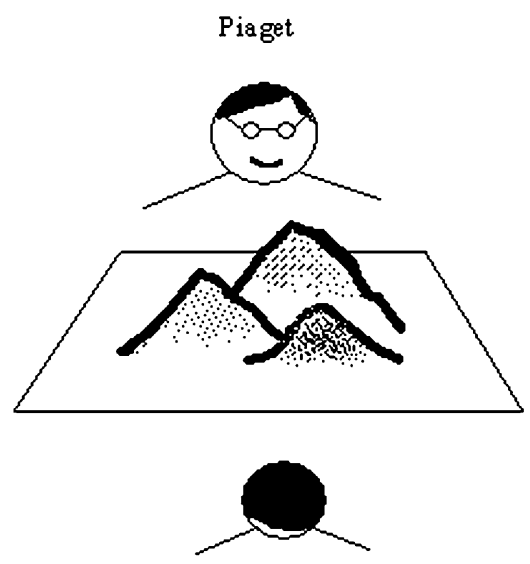

The child
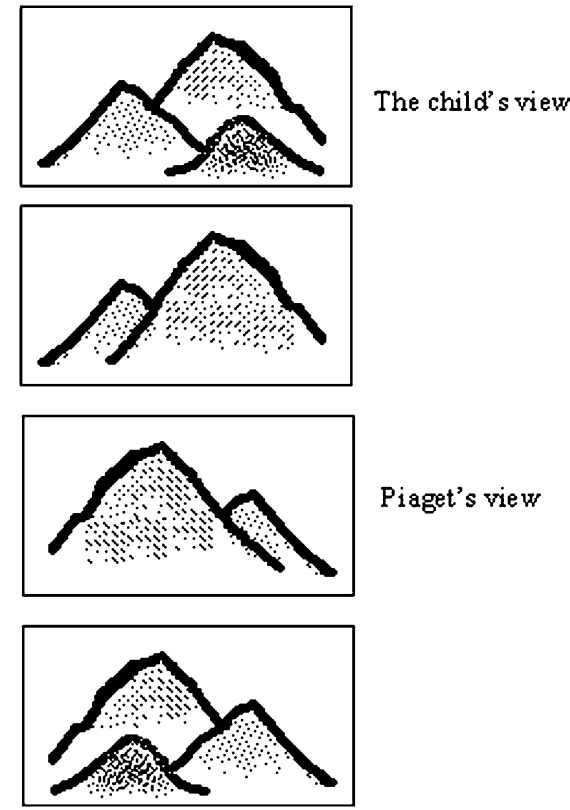

Fig. 1. The three mountains problem (Piaget \& Inhelder, 1948). Piaget asks the children to pick from four pictures the view that he, Piaget, would see. Younger children would pick the picture of the view they themselves see. Older children pick correctly. 
impaired. This led him to conclude that egocentrism was not a useful concept to explain the social impairment in autism.

Piaget's theory of egocentrism has not gone unchallenged (for a review, see Perner, 1991). Likewise, Rochat (1995) showed that children as young as 3 years old are able to discriminate what is reachable for themselves from what is reachable for someone else. He concluded:

From 3 years of age, young children are clearly capable of perspective taking, spatial decentration, and are flexible in adopting an egocentric or an allocentric perspective, depending on the requirements of the task (Rochat, 1995, p. 12)

Piaget and Rochat disagree about the age at which children can take someone else's point of view, and we do not intend here to settle this debate. Rather, we would like to argue that both of them have confounded the egocentric (versus allocentric) stance with role-taking. The three mountains problem supposes that the subject takes someone else's visuo-spatial but still egocentric perspective. The affordance of reachability makes sense only for an agent, whether it is the self or the other. When reaching for an object the location of the object has to be encoded in relation to the agent's body. Therefore, the task always relies on an egocentric representation of the object and cannot inform us about the allocentric perspective-taking ability of young children. This echoes the contention of Vogeley and Fink (2003, p. 39) that "the difference between first- and thirdperson-perspective is that 3PP necessitates a translocation of the egocentric viewpoint."

We do not claim here that the third-person perspective is always egocentric. Instead we claim that the traditional distinction in the literature between first- and third-person perspective is focused on the centre of reference (self versus other) and does not concern the perspective adopted on this centre of reference (egocentric versus allocentric). Consequently, it does not make a distinction between second-person and third-person perspective, a dimension that we believe has been overlooked in the mindreading literature to date.

\subsection{Egocentric versus allocentric viewpoint in spatial cognition}

The distinction between egocentric and allocentric representations was first made in spatial cognition. The core hypothesis is that the spatial location of an object can be encoded in two different ways. First, it can be encoded in its perceptual relation to the agent (e.g., the apple is in front of $\mathrm{me}$ ). This egocentric representation of the location is directly linked to the actions that the agent can perform toward the object: it is only if I know where the apple is relative to my body that I can reach it. The egocentric frame of reference is thus centred on the agent, whether the agent is me, you, or a third person.

The allocentric representation of the object is in terms of its surroundings independently of the agent (the apple is on the table). The object thus exists even if there is no relation with the self or another person. Consequently, allocentric representations do not change if the agent moves. In contrast to egocentric representations, which depend on the relationship between the object and the agent, allocentric representations maintain some kind of invariance of the perceived item relative to the agent. Furthermore, an allocentric representation of an object allows one to link this object to other objects, again independently of the agent.

Egocentric representations allow visuo-motor transformations, which lead to actions, but these representations are of little value when making a conscious perceptual judgement. Objects have to 
be perceived in their mutual relationship in allocentric coordinates to be perceived in their own right and to give rise to perceptual judgements according to the "constraint of contrastive identification" (Jacob \& Jeannerod, 2003). For instance, to see that the shape of the object is cylindrical, one needs to be able to compare different instantiations of this shape, that is, different objects that are also cylindrical.

This dual encoding has been shown at the neural level in a distinction between two kinds of neurons in the parietal cortex (Sakata \& Kusunoki, 1992). Some are dedicated to the position of the visual stimuli presented to an immobile observer in a frame of reference centred on the object. Others are dedicated to the stimuli in relation to the agent's actions in a frame of reference centred on the agent's body (relative to eye, head, and body position in space). This distinction between egocentric and allocentric spatial representations has been confirmed by a double dissociation between apperceptive agnosia and optic ataxia (for a review, see Jeannerod, 1997). For instance, Milner and Goodale's famous patient DF, who became an apperceptive visual agnosic, can reach and grasp simple shapes but is unable to judge their spatial properties or to compare two different items. In other words, she cannot translate her egocentric representation of the shape into an allocentric one. Conversely, AT, an optic ataxic patient is able to evaluate the size of an object but not to grasp it. She cannot represent the object relative to her body in egocentric coordinates. Interestingly, in everyday life, it is better to be optic ataxic than agnosic, as it is the latter patients who are more deeply handicapped (Jacob \& Jeannerod, 2003).

This distinction between space perception and visuo-motor transformation illustrates a dissociation between the visual systems that mediate object knowledge and object-directed action (Milner \& Goodale, 1995). Can a similar dissociation be found in theory of mind between target knowledge based on allocentrism and target-directed action based on egocentrism?

\subsection{Egocentrism versus allocentrism in social cognition}

We propose that we attribute mental states to an agent by adopting either an egocentric or an allocentric stance. Here, two questions can be raised:

- About the target: to whom do I attribute mental states, to myself or to another?

- About the stance: according to which stance do I represent the target, egocentric or allocentric? In this framework, both the first- and the third-person perspective may be either egocentric or allocentric.

The idea of different stances adopted towards the same individual has been traditionally developed in philosophy of language. For instance, Ernst Mach reported that one day on the bus he noticed a man that looked like a shabby pedagogue and then realized that he was looking at his own reflection on a mirror (Perry, 1997). In this example, Mach has two attitudes toward himself. At the beginning, he refers to himself through a detached description ("the man who looks like a shabby pedagogue") and only afterwards does he refer to himself as himself. Interestingly, the two attitudes (called de dicto and de se) cannot be reduced one to the other. Let us imagine that someone's trousers are on fire. As long as I do not realize that it is my own trousers that are on fire, I cannot take appropriate action (Kaplan, 1989). Neither can de se attitudes be reduced to de re propositions using a demonstrative ("that man whose trousers are on fire"). 
Despite being from a first-person perspective - that man considered as the man that $I$ see-this proposition remains allocentric. The first-person pronoun cannot be replaced by any other descriptions or proper names, even if they refer to the same individual. It plays a unique cognitive role, as it is directly connected to actions. Conversely, any description, however accurate and specific, will always leave open the possibility that the subject does not recognize himself in the description.

We would like here to suggest that these two attitudes toward the self correspond to two kinds of representation: egocentric and allocentric. Egocentric representations of the self derive from a direct knowledge attached to the self, while allocentric representations of the self derive from a detached knowledge of the person that one happens to be (Perry, 2002; de Vignemont, 2005). In the former case, one has privileged direct self-knowledge, which one cannot have about anybody else. In the latter case, one represents oneself as a person among others.

Similarly, we would like to suggest that the other could also be represented according to an egocentric or an allocentric stance. Indeed, the social world involves not only a first-person (the self) and a third-person (the other unrelated to the self), but also a second-person (the other related to the self), the distinction between the latter two perspectives being neglected by the literature on role-taking. Taking an egocentric stance means that others are represented only because they are related to the self in one way or another. Conversely, taking an allocentric stance means that the existence and/or mental states of others are completely independent from the self.

An egocentric stance represents the relationship between an individual (be it an object or a person) and the self. In the case of spatial cognition, the nature of this relation seems quite clear. An object either can be in extra-personal space located in allocentric coordinates, or in peri-personal space (for object-directed actions) located in egocentric coordinates. However, it seems less clear in social cognition. The boundaries between extra-personal and peri-personal social space are blurred. Intuitively, we would like to claim that the egocentric stance is based on direct social relationship. The complexity of the social network is such that it is difficult to specify more precisely what we mean. A range of different situations may arise:

- The subject actively participates in a self-centred situation (like his own birthday party).

- The subject actively participates in a self-related situation as one among others (like a football game).

- The subject witnesses an external self-related situation (like people talking about him).

- The subject witnesses an external self-unrelated situation (like a football game on TV).

In all these situations, the subject is in a direct physical and perceptual relationship with others. However, the relation is less and less strong. We propose that we adopt an egocentric stance when we ascribe mental states (1) that are explicitly related to us or (2) that are relevant for us and implicitly related to us. This notion of relevance may vary and we would like here to suggest that people with AS stretch this notion of relevance more than normal adults, applying it when it does not seem to be appropriate.

One intriguing consequence is that someone ceases to exist according to an egocentric stance when this person goes outside the social realm of the self. For instance, children have trouble understanding that their mother has a life of her own, outside of her relation to them. If we were unable to adopt an allocentric stance, then our understanding of the social world would be very 
impoverished, and probably inaccurate. Strawson (1959) and Evans (1982) emphasize the importance of being able to ascribe mental states to different persons in order to grasp their meaning. According to Evans's Generality Constraint, I can properly think that I am angry only if I am able to think that Kathy is angry or Harry is angry. We suggest that this is true not only for simple mental states with one argument (the subject), but also for states and behaviours with two arguments (the subject and another agent). Consequently, one could suggest that a proper grip on folk psychology requires understanding that relations are not only between oneself and someone else, but also between two external persons unrelated to oneself. I can think that I am jealous of Kathy only if I am able to report that Harry is jealous of Kathy or that Peter is jealous of Susan. It is only by taking an allocentric perspective that one can fully understand social relationships. Therefore, purely egocentric mentalizing would lead someone to a defective folk psychology.

This does not mean that egocentric mentalizing has no purpose. The reverse question can also be asked: what would happen if we had only an allocentric representation of others and ourselves? If you do not understand how you are related to the others, if you do not know your social location relative to them in an immediate way, you may suffer from poor social interactions. You may lack an "immediate, pre-reflective, or implicit understanding of the meaning of social interaction" (Zahavi \& Parnas, 2003). You may try to compensate for your lack of egocentric representations of others by using your allocentric social knowledge. Yet, this knowledge will not have been acquired on the basis of normal social experience and may result in a set of abstract rules. The allocentric stance is detached from interactions with people, while the egocentric stance is immersed in social interactions and directly connected to them. As we noticed earlier, it is only if we are able to connect something or someone to ourselves that we can act properly.

There seems therefore to be a mutual dependency between egocentric and allocentric stances. The allocentric social knowledge is partly based on memories of past egocentric interactions and inferences drawn upon them. The egocentric stance is influenced by a wider allocentric knowledge of people. A rich social life is thus based on egocentric mentalizing, balanced by allocentric mentalizing, which provides an accuracy check on the mental states of other people (see Table 1).

Based on this distinction, we can suggest a triangle model as in Fig. 2A such that the other can be understood either according to an egocentric stance ("you") or to an allocentric stance ("he/ she/they"). We suggest that people suffering from Asperger syndrome are likely to represent others predominantly in relationship to themselves, as per the "star shape" model centred on the self in Fig. 2B, while mutual relations between others are not represented. A consequence of this selfcentred model might be that only the people related to the Asperger individual will be truly considered as persons with mental states, while the others would be considered "as furniture" (Gerland, 1997, p. 64). In naïve egocentrism, the self is the only point of reference.

Table 1

Main features of egocentric and allocentric stance

\begin{tabular}{lll}
\hline & Egocentric stance & Allocentric stance \\
\hline Communication device & Second-person & Third-person \\
Epistemic basis & Direct relationship with the other & Any kind of relationship \\
Attitude & Immersed & Detached \\
Subject-dependency & Subjective & Objective \\
Function & Social interaction & Folk psychology \\
\hline
\end{tabular}



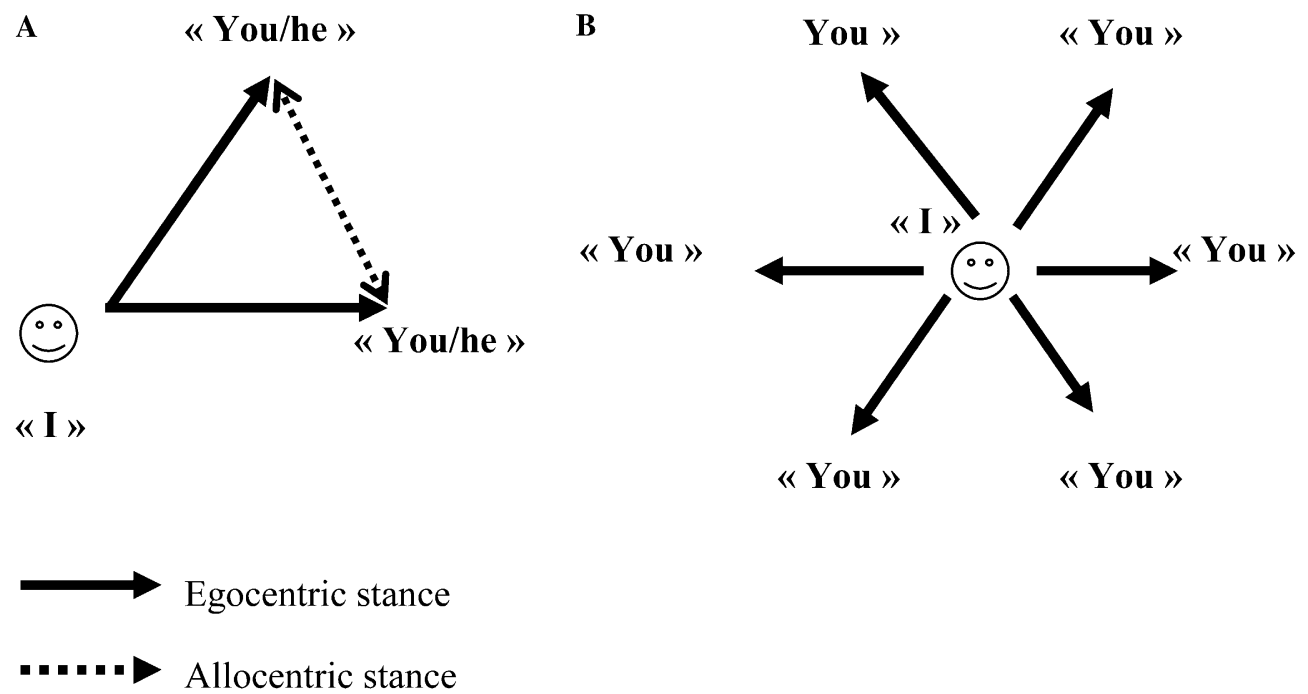

Fig. 2. The social world involves a first-person (the self), a second-person (the other related to the self) and a thirdperson component (the other unrelated to the self). (A) Triangle model: one can mentalize from an egocentric point of view when the other is related to the self and from an allocentric point of view when the other is not related to the self, but to other people. (B) Star model: the allocentric stance is impaired and the social world is self-centred. People do not exist by themselves, but only relative to their relationship with the subject.

\section{Mentalizing ability in Asperger syndrome}

We have discussed the distinction between egocentrism and allocentrism in some detail because we believe that the distinction is useful when we try to understand the limitations of mentalizing in Asperger syndrome. What are these limitations? In this next part we will review the evidence for both failures and successes on mentalizing tasks. After this, we will illustrate social difficulties with real life examples provided largely by AS individuals themselves. We will try to show that it would be a mistake to consider these anecdotes as deriving from a particular personality feature. Instead, they can be systematically understood as the consequences of an imbalance between egocentric and allocentric stances. We will attempt to refine these ideas with regard to mentalizing in the final section of this paper.

\subsection{Limitations on mentalizing in Asperger syndrome}

While the first empirical tests of the mindblindness hypothesis were carried out with relatively young and/or low-functioning children (Baron-Cohen, Leslie, \& Frith, 1985), it soon became clear that success on these tasks was achieved by autistic children who reached a verbal mental age of about 10 or above (Happé, 1995). Thus, the current assumption is that more able children with autism spectrum disorder gradually acquire an understanding of mental states, albeit with a delay of about 5 years (in terms of verbal mental age) compared to normally developing children. This huge delay suggests that late-acquired theory of mind is not the same as early-appearing intuitive mentalizing ability. 
Impairment on standard tests of theory of mind, such as false belief understanding, is less severe in children with Asperger syndrome than in children with autism (Ziatas, Durkin, \& Pratt, 1998, 2003), and in some cases of AS adults none or very little impairment may be found (e.g., Bowler, 1992; Dahlgren \& Trillingsgaard, 1996; Ozonoff, Rogers, \& Pennington, 1991). Impairments have been documented, however, in a number of studies with more complex theory of mind tests. These include stories requiring attribution of speaker's intentions (Happé, 1994; Jolliffe \& Baron-Cohen, 1999; Kaland et al., 2002), tests of judging mental state from the eyes or from the voice (Baron-Cohen, Jolliffe, Mortimore, \& Robertson, 1997; Kleinman, Marciano, \& Ault, 2001; Rutherford, Baron-Cohen, \& Wheelwright, 2002), understanding faux-pas (Baron-Cohen, O'Riordan, Stone, Jones, \& Plaisted, 1999) and video-clips of situations that are close to real life encounters (Channon, 2004; Heavey, Phillips, Baron-Cohen, \& Rutter, 2000). A mild degree of mentalizing impairment is compatible with either compensatory learning or a milder initial deficit. A continuing impairment is evident in very able AS adults when implicit (on-line) theory of mind tasks are used, such as attribution of mental states to moving geometric shapes (Abell, Happé, \& Frith, 2000; Castelli, Frith, Happé, \& Frith, 2002; Klin, 2000).

Performance on standard false belief tasks has been shown to be subject to improvement with training (Hadwin, Baron-Cohen, Howlin, \& Hill, 1997; Kloo \& Perner, 2003; Ozonoff \& Miller, 1995; Wellman et al., 2002). It is therefore possible that the relatively good performance of able and older individuals with Asperger syndrome on these tasks is due to extended practice. This practice might make use of certain heuristics (e.g., when an event occurs and a person is not present, the event is ignored or cancelled), which in turn might involve verbal or pictorial strategies to facilitate the understanding of the contents of other minds, as suggested for instance by Hurlburt, Happé, and Frith (1994). Thus, people with autistic disorder may use their ability to visualize and reflect on images and words to gain an understanding of the representational nature of beliefs.

One observation that is difficult to reconcile with the idea of a mentalizing impairment is the heightened sense of self that individuals with Asperger syndrome exhibit. Asperger himself acknowledged this fact:

These children observe themselves constantly. They are an object of interest to themselves, and they direct their attention towards the functions of their body. (Frith, 1991 translation, p.73)

Furthermore, there are an ever-increasing number of autobiographical accounts, which attest to intense desire and high ability to introspect. Biographical accounts as well as countless anecdotal examples show that people with Asperger syndrome do reflect on their own feelings and thoughts.

There is experimental evidence, too. People with Asperger syndrome asked to reflect on their inner states are capable of doing so, in line with their ability to reason about mental states in false belief tasks. This was demonstrated by Hurlburt et al. (1994). Yet during this experiment it was observed that the AS individuals had no interest whatever in comparing their own self-reports with those of others, contrary to normal adults. Likewise, a lack of interest in gossip or fictional literature and movies suggests there is little interest in analyzing the feelings of other people unless they relate to the self. 
There is sufficient evidence at present to accept that a degree of mentalizing impairment, perhaps only a delay, is present in AS. Does it make sense to talk of a mild degree of mentalizing impairment? Why does mentalizing appear to be successfully mastered in some but not all situations?

It is possible that AS individuals are limited in their ability to attribute mental states to others because they are often locked into an egocentric perspective. Extreme egocentrism (or egocentricity) has been highlighted by Gillberg and Gillberg (1989) in their diagnostic criteria for AS as the way of characterizing social impairment:

Social impairment with extreme egocentricity, which may include:

- Inability to interact with peers.

- Lack of desire to interact with peers.

- Poor appreciation of social cues.

- Socially and emotionally inappropriate responses.

We would like here to give concrete examples that illustrate and refine this schematic list. Importantly egocentrism here is not to be confused with ordinary selfishness, egotism, or calculated lack of consideration for others. Below we provide some preliminary and anecdotal evidence for our proposal with annotated examples. These are taken from autobiographical writings by authors with AS (Gerland, 1997; Lawson, 1998; Sainsbury, 2000; Willey, 1999).

\subsection{A Self-centred World}

Can the social world of AS individuals be depicted with the "star shape" model centred on the self? Indeed, most of the time they prefer to be on their own. For instance, Willey (1999, p. 35) says: "My own conversations and thoughts were always my best friends. I was happy spending time with only me, happy to talk to myself and happy to entertain myself." When they are not alone, their relationships to others remain still self-centred.

\section{Own point of view is paramount}

AS individuals are very interested in themselves, but they do not seem to feel the need to compare themselves with others. They like to talk and write about themselves, as they see themselves. Other people's ideas and opinions are not as interesting as their own. Willey (1999, p. 28) reports: "It was easy for me to give my opinions on things, virtually all the time. I was by far the most blunt and outspoken of our group, even when my friends suggested I had gone too far, I never knew how far was too far. Even now, I cannot find one reliable reason for keeping my thoughts to myself."

Most of the time, AS individuals seem to believe that everybody should be interested in what they think. However, if they find out that other people are not so interested in them, then they can feel very despondent. Willey (1999) talks about being invisible when she started college (pp. 4344): "Soon, I found my steps were never followed and my phone was never called. Soon, I saw I was invisible. On one level this did not bother me. I liked my time alone and my personal space. But day in day out, rejection began to lay heavy on my shoulders most likely because I did not understand why I was excluded." 


\section{Difficulties in understanding other people's views}

Often AS individuals suppose that everybody has the same desires and beliefs as themselves, and they cannot understand the differences. Lawson (1998/2000, p. 57) says: "I thought everyone saw the world in the way I did, and it was very confusing for me when my delights and ecstasies were not seen or understood by other people." If they discover that people disagree with them, then they feel frustrated. In some cases the frustration felt at not getting one's own needs understood can evoke feelings of paranoia.

\section{The contented tyrant}

Just as young babies are sometimes described as tyrants, individuals with AS can be so described by their families. They tend to make other people do what they wish and often manipulate them successfully. They are happy if others do exactly what they want, and extremely frustrated if they do not. Charlotte Moore (2004) in her account of autism in her family says: "The Asperger child cannot accommodate a friend, unless the friend is prepared to obey his every command. Other people are all right, says John Peters, a grandfather with AS speaking on the BBC documentary 'The Autism Puzzle,' as long as they do exactly what you want.' (p. 69).

According to the egocentric stance the world is simple: do everything the ego wants and never thwart it. However, the tendency to tyranny can be overcome as shown by Willey (1999): "I caution myself never to overburden [my husband] with my needs, to never fall in on him, to lean on him only when I am faced with those things that toss me in circles and make me take unusual turns." (p. 71).

\section{Difficulties in avoiding egocentric relevance}

Ambiguous messages are known to be problematic for people with AS while other people often do not even notice ambiguity. It is possible that in some cases the ambiguity arises from interpreting the message as relevant to the self. RB, a highly intelligent and articulate woman with autism who often speaks at conferences, reported the following experience in one of her talks, which related to a well-known example of a pragmatic misunderstanding. RB was at her parents' house when the vicar phoned. She answered the phone, and when he asked if her mother was there, she answered truthfully "yes" and put the phone down. Her reasoning was as follows: The vicar is concerned about the well-being of the community; he is concerned about me; he wants to make sure that I am not alone in the house. The most likely interpretation of ambiguous messages is thus the one that refers to the self. Consequently, people with AS may interpret self-unrelated situations as being self-related.

\subsection{Relating to others}

Relationships to other people often seem to follow an all-or-none pattern. There are well-documented problems of working with others in groups and of fitting into groups, but there is also evidence that relationships to others are possible.

\section{Difficulties in understanding that others live their own lives}

From an egocentric stance other people are understood only relative to the self. AS people often think that they are the centre of other people's life and the only motivation for their actions and their discourse. Consequently, they cannot understand why people do not want to be friends with 
them. Lawson (1998/2000, p. 40) says: "I thought everyone saw things the same way I did, but my behaviour seemed to make people angry or cause them to distance themselves from me. I came to believe this was the case because I could never keep friends with anyone for very long. . . I never understood why they did not want to be with me." Other people do not seem to have a life by themselves; they exist only relative to the AS individual. For instance, Lawson (1998/2000, p. 15) complains: "Other people seemed to be there just to interrupt and disturb me, or demand from me. I responded with withdrawal or anger."

\section{Difficulties in working in a group}

A hallmark of Asperger syndrome is the difficulty they experience with group activities. Asperger (1944) said of his famous case Fritz V.: "From the moment he set foot on the ward he stood out from the rest of the group and this did not change. He remains an outsider. . It was impossible to get him to join in group play" (p. 42, Frith translation 1991). It has often been observed that even very articulate AS individuals are much more capable in handling one on one interactions than interactions in small groups. An anonymous student (Sainsbury, 2000, p. 50) says: "I usually don't know how to participate in group work and am blamed for not participating." More generally, they have difficulties in fitting in a social group when true collaboration is needed, where an allocentric stance is clearly useful. Similarly, they do not really understand the notion of close relationships: "I didn't know how to have a relationship. I didn't know what the point was or what it was you were supposed to do with the man you were together with... I didn't grasp at all what it meant just to be with each other, what other couples seemed to do." (Gerland, 1997, p. 185).

\section{Evidence of relationships with others}

Even though it is rare for AS individuals to find lasting friendship and marriage, and to have children of their own, such cases have been documented, and their success needs to be explained. Willey (1999) movingly talks about her feelings about her husband and children with lucid insight: "I worry a lot about the influence I have on my daughters' self-esteem and their happiness. ...I can be extremely invasive and obsessive and blunt and loud. I routinely assault my children's quiet and their reflections." (p. 81). We suggest that AS individuals perform best in attributing mental states to themselves and to another if that person's mental states refer to themselves. People who are related to the self and care about the self, such as mother, sibling, partner, have in this sense a privileged status.

Conversely, AS individuals do not like to meet new people and find it hard to relate to strangers. Gerland (1997) reports the first time she had been to playschool: "Everyone I didn't know had an empty face, which meant everyone except my family. I didn't realize that these faces were people in the same way as those I knew were people. Those faces were as lacking in content as furniture" (p. 64). They may use their preserved mentalizing abilities for their relatives, but not for strangers. Once they have formed a close relationship it is clear that they try hard to maintain it and can succeed when they have the full cooperation of the other person.

\subsection{Taking an abstract stance to social relationships}

Having given a number of examples that are interpretable in terms of extreme egocentrism, we now wish to draw attention to the fact that AS individuals are also capable of taking an extreme 
allocentric stance. For instance, Lawson (1998/2000, p. 1) starts her personal account with this poignant paragraph: "One of the best ways of understanding what autism is like is to imagine yourself as a perpetual onlooker. Much of the time life is like a video, a moving film I can observe but cannot reach. The world passes in front of me shielded by glass."

AS people are famed for being able to adopt an unbiased and highly abstract stance towards the social world, like "an anthropologist on Mars" (Sacks, 1995). They thrive on the idea of rules. This is shown whenever AS individuals talk about generalities of how people with AS behave, and about rules that other people might follow in their social interactions that they feel they have worked out by logical analysis. For instance, they have written eloquently about misunderstandings and miscarriages of justice in general and they can be successful advocates of the plight of AS people (Sainsbury, 2000; Willey, 1999). They have high-level social knowledge and are able to see social structures and relationships in a detached way that can give rise to the impression that they are cold and distanced. However, their personal logic of how the social world should work may be very formal and far from reality.

For example, on the web one can find "A survival guide for people with Asperger syndrome," which includes a large number of social rules. The author, Marc Segar, writes in the introduction to his guide: "I wish to lay out a set of rules and guide-lines, in a style similar to that of the highway code...You might think that these are the rules to a rather silly game, but the game is life and the rules cannot be changed." One example of such rules applies to how to find out who your friends are and how to behave with them. There is nothing spontaneous in these rules. For instance, he says: "Try to show that you like them [your friends] using the rules given under eye contact."

Similarly, RL told us that he did not understand why he should not tell his boss when his colleagues were not working hard enough, nor did he understand why his colleagues did not like him because of that. For him, doing your best is what you are supposed to do and everybody should follow this rule. Job after job, he repeated the same mistake, never learning that the social rule can sometimes override the general rule.

The behaviour pattern of AS individuals does not fit any traditional theory of mindreading. On the contrary, it reveals the oversimplified way in which we conceptualize social cognition. We have therefore tried to provide a new theoretical framework that enables us to account for-or at least to analyze in more detail-naïve egocentrism in AS. We claim that Asperger people are most successful at mentalizing when they display naïve egocentrism. We hypothesize that while mentalizing, people with AS are unable to connect an egocentric to an allocentric stance and can only adopt extreme forms of either.

\section{An imbalance between naïve egocentrism and abstract allocentrism}

The main presenting feature in everyday social interactions, as illustrated in our examples, is what we have termed naïve egocentrism. This is akin to the normal egocentrism of small children, which they normally grow out of, and which parents find charming in babies but not in older children or adults. Why might people with AS be stuck in this developmentally immature stance? We propose three types of causes, but we do not exclude other possibilities (see Fig. 3). 


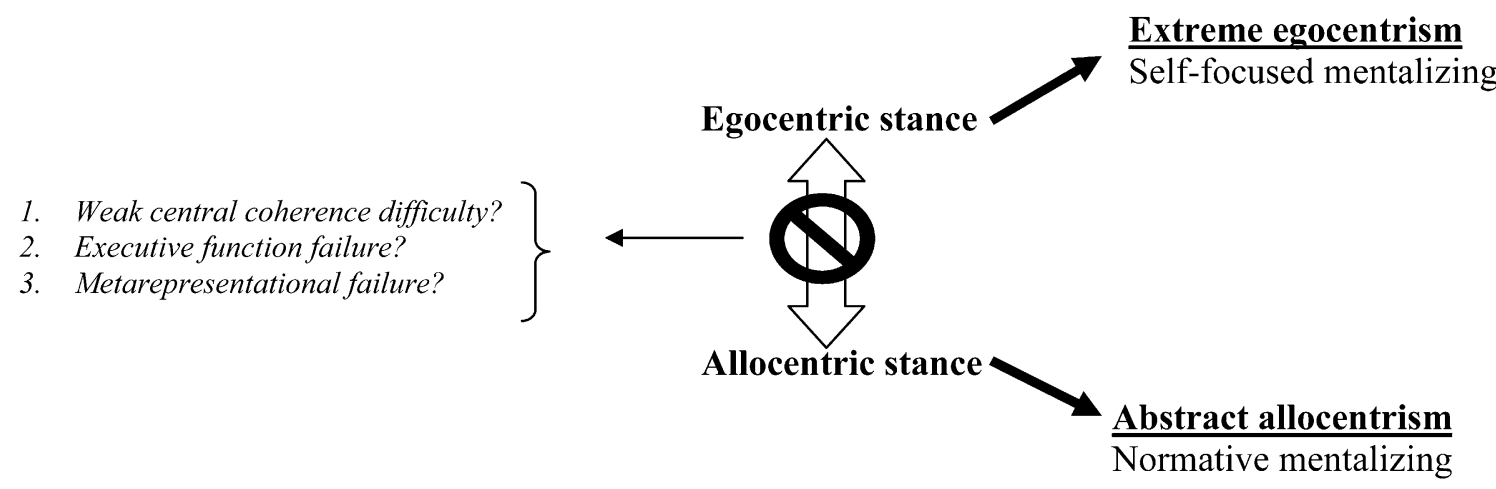

Fig. 3. In normal adults, the egocentric and allocentric stances interact with each other, allocentric knowledge of others being based on egocentric interactions and conversely, allocentric knowledge of others influencing our egocentric interactions. In AS there could be a breakdown of this mutual dependency, caused by several possible cognitive deficits. This disconnection leads to a polarization of egocentric and allocentric stances.

Hypothesis 1. Informational complexity and weak central coherence.

One hurdle for the ability to move on from egocentrism may be informational complexity. An allocentric stance requires mastering more information than the egocentric stance and adds a further dimension (see Fig. 2). In the case of egocentrism, assuming privileged first-person access, when children interact with someone else they already understand half of the relationship, that is, what they themselves feel and believe. All they have to do is to interpret the behaviour of the other, and they tend to interact only with people with whom they are familiar, and with only one person at a time.

By contrast, allocentrism requires them to understand the social interaction between two or more external people. Therefore, they need to process more information about different individuals at the same time. It seems that normal children in pre-school years are able to achieve this developmental step, regardless of general ability (Hay, Payne, \& Chadwick, 2004), even if mentalizing seems to be at its best in a one-to-one situation and more difficult when a number of different protagonists have to be monitored in a group interaction. Why not children with autism or Asperger syndrome? It is well established that children with autistic spectrum disorder have difficulties integrating overall contextual information, while at the same time they excel at processing information piecemeal (Frith, 2003; Happé, 1999). It would be possible therefore to explain naïve egocentrism as a consequence of so-called weak central coherence. A prediction from this hypothesis is that there should be a relationship between performance on central coherence tests and performance on a test designed to assess the extent of egocentrism.

Hypothesis 2. Switching between stances and executive function failure.

A second possible reason relates to the difficulty in high-level executive function that has been found to be associated with autism spectrum disorder at all levels of ability (see review by Hill, 2004). Taking an allocentric stance when appropriate requires a high-level mechanism that controls the switching between the two stances, a control mechanism that might be impaired or absent in AS (see Frith, 2003 for speculations on the consequences of a missing homunculus). 
According to this proposal, we would seek to explain a tendency to be developmentally stuck by perseveration in an egocentric stance that may be primary in development. This explanation embraces the possibility that AS individuals do not actually lack the ability to adopt an allocentric stance, but merely find the switch from egocentric to allocentric stance very effortful. The prediction would be that once they have adopted an allocentric stance, they would find it difficult to switch back again.

This sort of mechanism could also explain the apparent disconnection between naïve egocentrism and abstract allocentrism that we tentatively propose. In AS, allocentrism is a priori, ruled by logic, rather than a posteriori, based on the laws drawn from past experiences. AS individuals manipulate mental states as if they were numbers to add and subtract, resulting in unrealistic and sometimes highly idealized systems for understanding social relations. In contrast, the normal allocentric stance is tempered by constant reference to egocentric viewpoints and tends therefore to strive towards more realistic social schemes.

Even if egocentrism and allocentrism are distinct stances, they still interact most of the time. Indeed, we can entertain both perspectives on someone and modify our egocentric judgment by taking a more allocentric view. For example, a child may have experienced her mother as being rather stingy in giving gifts to her, but once she discovers that the mother is involved in a charity organization that distributes aid to disadvantaged people, she would adjust her evaluation of her apparent lack of generosity. We do not know whether this possibility is equally open to AS people. We would predict that there would be a relationship between switching stances and performance on other executive switching tasks, such as have been developed by Burgess (2000).

Hypothesis 3. Confusing subjective and objective stances and metarepresentational failure.

It is possible that naïve egocentrism and subtle mentalizing failure are more intimately connected. Being developmentally stuck in an egocentric stance may not be due to other cognitive problems, but due to limitations in the capacity to mentalize itself. Thus it could be due to a failure in the metarepresentational mechanism that is postulated to underlie mentalizing (Leslie, 1987). Thus, when we normally attribute mental states to someone else while taking an egocentric stance, we are implicitly aware that our representation is egocentric. Similarly, when we locate an object relative to our body, we know implicitly that this location is accurate only within an egocentric frame of reference. Possibly, AS people do not represent their perspective as being egocentric, but rather as being objective and self-independent. If they do not realize that their perspective is subjective then they confound egocentrism and allocentrism. Consequently, they do not understand that other people's mental states are different from their own. This hypothesis predicts that the more severe the mentalizing impairment, the more severe the egocentrism and the less likely the adoption of an allocentric stance.

We freely admit that we cannot exhaustively account for even a fraction of the social behaviour associated with Asperger syndrome. We have tried here to provide a more fine-grained analysis of some aspects of their awareness of self and others, but a lot remains to be done both from an experimental and a theoretical point of view. An interesting study in this area was carried out by Langdon and Coltheart (2001), who have adopted a related distinction regarding visuo-spatial perspective-taking in schizotypy and schizophrenia. They propose that schizotypy is associated with a lack of allocentric perspective. Indeed, delusions of reference are nothing other than interpreting in a self-related way something self-unrelated. Similarly, aggressive children show an 
asymmetry related to the self, their understanding being biased by egocentrism. They over-attribute hostile intentions to a character acting towards themselves (in vignettes) but not towards third parties (Dodge \& Frame, 1982). Further experimental studies are now needed to investigate this question by contrasting egocentric and allocentric stances in both spatial and social domains and for other pathologies.

\section{Conclusions}

In this paper, we have been trying to reconcile the subtle mentalizing impairments in Asperger syndrome, their highly abstract social understanding and their limitations in on-line social interactions. We took the view that the distinction between first-person and third-person perspective does not capture the difficulties in mentalizing, and that the distinction between egocentric and allocentric stances is more critical. To support this claim we have provided a number of illustrative examples of an egocentric stance in self-reports. These show that a naïve egocentrism is a common source of difficulty in social interchanges as experienced by individuals with AS. We also suggest that individuals with AS are sometimes able to take a stance that suggests an extremely abstract kind of allocentrism. Without ruling out other explanations, we propose three hypotheses, each linked to cognitive problems already identified in autistic disorders (for a review see Frith, 2003). Thus we predict that a lack of allocentric stance could relate to weak central coherence, a lack of switching could relate to executive function problems, and a confusion between subjective and objective stances could relate to metarepresentational failure.

We would like to argue that, regardless of the particular hypothesis preferred, the mentalizing limitations in AS can be better understood in terms of a disconnection between egocentrism and allocentrism. Normally we constantly switch between egocentric and allocentric stances, and we know the difference. Allocentrism and egocentrism are complementary. In order to go somewhere, you need both a map made by people who have actually moved around the city and you need to know your own location on the map. It seems to us that people with AS either look at a map of a city that does not exist or see small signs saying "You are here" everywhere. It is only when we are able to adopt an allocentric stance that we can truly know what it is to be egocentric, and it is only when we are able to adopt an egocentric stance that we can achieve an allocentric understanding of others.

\section{Acknowledgments}

This work was supported by MRC programme Grant G9617036 to U.F. and a Marie Curie Fellowship to F.V.

\section{References}

Abell, F., Happé, F., \& Frith, U. (2000). Do triangles play tricks? Attribution of mental states to animated shapes in normal and abnormal development. Journal of Cognitive Development, 15, 1-20. 
Asperger, H. (1944). Die autistischen Psychopathen im Kindesalter, Archiv für Psychiatrie und Nervenkrankheiten (Vol. 117, pp. 76-136). Translated by U. Frith (Ed.). In Autism and Asperger Syndrome (pp. 37-92). Cambridge: Cambridge University Press, 1991.

Baron-Cohen, S. (1995). Mindblindness. An essay on autism and theory of mind. Cambridge, MA: MIT Press.

Baron-Cohen, S., Leslie, A. M., \& Frith, U. (1985). Does the autistic child have a "theory of mind?. Cognition, 21, 37-46.

Baron-Cohen, S., Jolliffe, T., Mortimore, C., \& Robertson, M. (1997). Another advanced test of theory of mind: Evidence from very high functioning adults with autism or Asperger syndrome. Journal of Child Psychology and Psychiatry, 38(7), 813-822.

Baron-Cohen, S., O'Riordan, M., Stone, V., Jones, R., \& Plaisted, K. (1999). Recognition of faux pas by normally developing children and children with Asperger syndrome or high-functioning autism. Journal of Autism and Developmental Disorders, 29(5), 407-418.

Bowler, D. M. (1992). "Theory of mind" in Asperger's syndrome. Journal of Child Psychology and Psychiatry, 33(5), 877-893.

Burgess, P. W. (2000). Strategy application disorder: The role of the frontal lobes in human multitasking. Psychological Research, 63(3-4), 279-288.

Castelli, F., Frith, C. D., Happé, F., \& Frith, U. (2002). Autism, Asperger syndrome and brain mechanisms for the attribution of mental states to animated shapes. Brain, 125, 1839-1849.

Channon, S. (2004). Frontal lobe dysfunction and everyday problem-solving: Social and non-social contributions. Acta Psychologica, 115(2-3), 235-254.

Dahlgren, S. O., \& Trillingsgaard, A. (1996). Theory of mind in non-retarded children with autism and Asperger's syndrome. A research note. Journal of Child Psychology and Psychiatry, 37(6), 759-763.

Dennett, D. C. (1987). The intentional stance. Cambridge, MA: MIT Press.

Dodge, K. A., \& Frame, C. L. (1982). Social cognitive biases and deficits in aggressive boys. Child Development, 53(3), 620-635.

Evans, G. (1982). In: J. MacDowell (Ed.), The varieties of reference. Oxford: Oxford University Press.

Farrer, C., \& Frith, C. D. (2002). Experiencing oneself vs. another person as being the cause of an action: The neural correlates of the experience of agency. Neuroimage, 15, 596-603.

Frith, U. (2001). Mind blindness and the brain in Autism. Neuron, 32, 969-979.

Frith, U. (2003). Autism: Explaining the enigma (2nd ed.). Oxford: Blackwell.

Frith, U. (2004). Emmanuel Miller lecture: Confusions and controversies about Asperger syndrome. Journal of Child Psychology and Psychiatry, 45, 672-686.

Gerland, G. (1997). A real person. Life from the outside. Translated from the Swedish. London: Souvenir Press.

Gillberg, I. C., \& Gillberg, C. (1989). Asperger syndrome-some epidemiological considerations: A research note. Journal of Child Psychology and Psychiatry, 30, 631-638.

Gopnik, A. (1993). How we know our minds: The illusion of first-person knowledge of intentionality. The Behavioral and Brain sciences, 16, 1-14.

Gopnik, A., \& Astington, J. (1988). Children's understanding of representational change and its relation to the understanding of false belief and the appearance-reality distinction. Child Development, 59, 26-37.

Hadwin, J., Baron-Cohen, S., Howlin, P., \& Hill, K. (1997). Does teaching theory of mind have an effect on the ability to develop conversation in children with autism?. Journal of Autism and Developmental Disorders, 27(5), 519-537.

Happé, F. (1994). An advanced test of theory of mind: Understanding of story characters' thoughts and feelings by able autistic, mentally handicapped, and normal children and adults. Journal of Autism and Developmental Disorders, 24(2), 129-154.

Happé, F. (1995). The role of age and verbal ability in the theory of mind task performance of subjects with autism. Child Development, 66(3), 843-855.

Happé, F. (1999). Autism: Cognitive deficit or cognitive style?. Trends in Cognitive Sciences, 3(6), 216-222.

Happé, F. (2003). Theory of mind and the self. Annals of the New York Academy Sciences, 1001, 134-144.

Happé, F., Ehlers, S., Fletcher, P., Frith, U., Johansson, M., Gillberg, C., et al. (1996). 'Theory of mind' in the brain. Evidence from a PET scan study of Asperger syndrome. Neuroreport, 20, 197-201.

Hay, D. F., Payne, A., \& Chadwick, A. (2004). Peer relations in childhood. Journal of Child Psychology and Psychiatry, 45(1), 84-108. 
Hill, E. L. (2004). Executive dysfunction in autism. Trends in Cognitive Sciences, 8, $26-32$.

Heavey, L., Phillips, W., Baron-Cohen, S., \& Rutter, M. (2000). The Awkward Moments Test: A naturalistic measure of social understanding in autism. Journal of Autism and Developmental Disorders, 30(3), 225-236.

Hobson, R. P. (1984). Early childhood autism and the question of egocentrism. Journal of Autism and Developmental Disorders, 14(1), 85-104.

Hurlburt, R., Happé, F., \& Frith, U. (1994). Sampling the form of inner experience in three adults with Asperger syndrome. Psychological Medicine, 24, 385-395.

Jacob, P., \& Jeannerod, M. (2003). Ways of seeing. New York: Oxford University Press.

Jeannerod, M. (1997). The cognitive neuroscience of action. Oxford: Blackwell.

Jolliffe, T., \& Baron-Cohen, S. (1999). The Strange Stories Test: A replication with high-functioning adults with autism or Asperger syndrome. Journal of Autism and Developmental Disorders, 29(5), 395-406.

Kaland, N., Moller-Nielsen, A., Callesen, K., Mortensen, E. L., Gottlieb, D., \& Smith, L. (2002). A new 'advanced' test of theory of mind: Evidence from children and adolescents with Asperger syndrome. Journal of Child Psychology and Psychiatry, 43(4), 517-528.

Kaplan, D. (1989). Demonstratives. In J. Almog, J. Perry, \& H. Wettstein (Eds.), Themes for Kaplan. New York: Oxford University Press.

Kleinman, J., Marciano, P. L., \& Ault, R. L. (2001). Advanced theory of mind in high-functioning adults with autism. Journal of Autism and Developmental Disorders, 31(1), 29-36.

Klin, A. (2000). Attributing social meaning to ambiguous visual stimuli in higher-functioning autism and Asperger syndrome: The Social Attribution Task. Journal of Child Psychology and Psychiatry, 41(7), 831-846.

Kloo, D., \& Perner, J. (2003). Training transfer between card sorting and false belief understanding: Helping children apply conflicting descriptions. Child Development, 74(6), 1823-1839.

Langdon, R., \& Coltheart, M. (2001). Visual perspective-taking and schizotypy: Evidence for a simulation-based account of mentalizing in normal adults. Cognition, 82(1), 1-26.

Lawson, W. (1998/2000). Life behind Glass. A personal account of autism spectrum disorder. London: Jessica Kingsley Publishers.

Leslie, A. (1987). Pretense and representation: The origins of Theory of Mind. Psychological Review, 94, 412-426.

Macintosh, K. E., \& Dissanayake, C. (2004). Annotation: The similarities and differences between autistic disorder and Asperger's disorder: A review of the empirical evidence. Journal of Child Psychology and Psychiatry, 45(3), 421-434.

Milner, D., \& Goodale, M. A. (1995). The visual brain in action. New York: Oxford University Press.

Moore, C. (2004). George and Sam. London: Penguin Books.

Nichols, S., \& Stich, S. (2003). Mindreading. Oxford: Oxford University Press.

Ozonoff, S., Rogers, S. J., \& Pennington, B. F. (1991). Asperger's syndrome: Evidence of an empirical distinction from high-functioning autism. Journal of Child Psychology and Psychiatry, 32(7), 1107-1122.

Ozonoff, S., \& Miller, J. N. (1995). Teaching theory of mind: A new approach to social skills training for individuals with autism. Journal of Autism and Developmental Disorders, 25(4), 415-433.

Perner, J. (1991). Understanding the representational mind. Cambridge, MA: MIT Press.

Perry, J. (1997). Myself and I. In M. Stamm (Ed.), Philosophie in Synthetischer Absicht (pp. 83-103). Stuttgart: KlettCotta.

Perry, J. (2002). Identity, personal identity and the self. Cambridge/Indianapolis: Hackett Publishing Company.

Piaget, J., \& Inhelder, B. (1948/1956). The child's conception of space. London: Routledge and Paul Kegan.

Rutherford, M. D., Baron-Cohen, S., \& Wheelwright, S. (2002). Reading the mind in the voice: A study with normal adults and adults with Asperger syndrome and high functioning autism. Journal of Autism and Developmental Disorders, 32(3), 189-194.

Rochat, P. (1995). Perceived reachability for self and for others by 3- to 5-year-old children and adults. Journal of Experimental Child Psychology, 59(2), 317-333.

Ruby, P., \& Decety, J. (2001). Effect of subjective perspective taking during simulation of action: A PET investigation of agency. Nature Neuroscience, 4, 546-550.

Ruby, P., \& Decety, J. (2003). What do you believe versus what do you think they believe. A neuroimaging study of perspective-taking at the conceptual level. European Journal of Neuroscience, 17, 2475-2480.

Sacks, O. (1995). An anthropologist on Mars. NY/London: Alfred Knopf/Picador. 
Sainsbury, C. (2000). Martian in the playground: Understanding the school child with Asperger syndrome. Bristol: Lucky Duck Publishing.

Sakata, H., \& Kusunoki, M. (1992). Organization of space perception: Neural representation of three-dimensional space in the posterior parietal cortex. Current Opinion in Neurobiology, 2(2), 170-174.

Strawson, P. F. (1959). Individuals. London: Lowe \& Brydone.

de Vignemont, F. (2005). Une question de perspective: égocentrisme et allocentrisme social. Confrontations psychiatriques (in press).

Vogeley, K., Bussfeld, P., Newen, A., Herrmann, S., Happe, F., Falkai, P., et al. (2001). Mind reading: Neural mechanisms of theory of mind and self-perspective. Neuroimage, 14(1), 170-181.

Vogeley, K., \& Fink, G. R. (2003). Neural correlates of the first-person-perspective. Trends in Cognitive Sciences, 7(1), $38-42$.

Vogeley, K., May, M., Ritzl, A., Falkai, P., Zilles, K., \& Fink, G. R. (2004). Neural correlates of first-person perspective as one constituent of human self-consciousness. Journal of Cognitive Neurosciences, 16(5), 817-827.

Wellman, H. M., Baron-Cohen, S., Caswell, R., Gomez, J. C., Swettenham, J., Toye, E., et al. (2002). Thought-bubbles help children with autism acquire an alternative to a theory of mind. Autism, 6(4), 343-363.

Willey, L. H. (1999). Pretending to be normal. Living with Asperger's syndrome. London: Jessica Kingsley.

Zahavi, D., \& Parnas, J. (2003). Conceptual Problems in Infantile Autism Research. Journal of Consciousness Studies, 10(9-10), 53-71.

Ziatas, K., Durkin, K., \& Pratt, C. (1998). Belief term development in children with autism, Asperger syndrome, specific language impairment, and normal development: Links to theory of mind development. Journal of Child Psychology and Psychiatry, 39(5), 755-763.

Ziatas, K., Durkin, K., \& Pratt, C. (2003). Differences in assertive speech acts produced by children with autism, Asperger syndrome, specific language impairment, and normal development. Development and Psychopathology, 15(1), 73-94. 